\title{
Research Paper \\ Structural Equation Modeling of Dysfunctional Attitudes and Depression Symp- toms: Investigation of the Mediation Role of Ruminative Response Style
}

\author{
*Hamid Reza Golzar' ${ }^{1}$, Abdolaziz Aflakseir², Javad Molazadeh²
}

1. MSc., Department of Clinical Psychology, Faculty of Education \& Psychology, University of Shiraz, Shiraz, Iran.

2. PhD of Clinical Psychology, Assistant Professor, Department of Clinical Psychology, Faculty of Education \& Psychology, University of Shiraz, Shiraz, Iran.

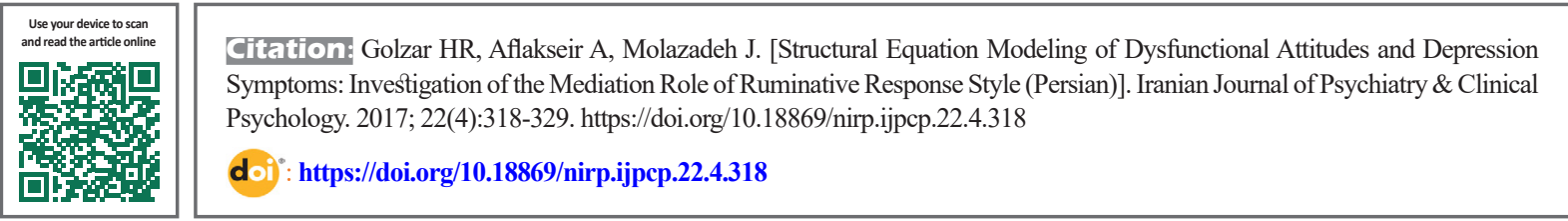

Received: 02 Jul. 2016

Accepted: 23 Oct. 2016

Key words:

Dysfunctional at-

titudes, Depression

Symptoms, Rumina-

tive response style,

Structural equation

modeling

\section{A B S T RACT}

Objectives The aim of this study was to investigate the mediation role of ruminative response style in the relationship between dysfunctional attitudes and depression symptoms.

Methods This correlational and descriptive study was conducted on 200 undergraduate students (99 females and 101 males) who were selected by convenience sampling method out of Shiraz University students in academic year 2012-2013. To measure the study variables, the revised form of depression scale, short form of dysfunctional attitudes scale and ruminative response style scale were used. To examine the study hypotheses, the simultaneous multiple regression model according to Baron and Kenny (1986) and structural equation modelling were used. To study the fitness of the proposed model, the absolute, adjusted and comparative fit indices and to determine the significance of indirect effect of moderate variable, the snowball sampling were used by SPSS16 and Amos graphic.

Results The results showed that dysfunctional attitudes were negative and significant predictor of depression symptoms both directly and indirectly through ruminative response style. Moreover, the results of the absolute (RMSEA=0.06), comparative $(C F I=0.97)$ and adjusted $(A G F I=0.91)$ fit indices showed that the proposed model had a close relationship with data of fitness sample and the theoretical assumptions. Conclusions Finally, the model parameters matched the model in terms of optimal fit.

\section{* Corresponding Author:}

Hamid Reza Golzar, MSc.

Address: Department of Clinical Psychology, Faculty of Education \& Psychology, University of Shiraz, Iran.

Tel: +98 (71) 53662371

E-mail: Hamidrezagolzar65@gmail.com 


\title{
مدلسازى معادلههاى ساختارى نكَرشهاى ناكار آمد و افسردتىى: بررسى نقش واسطهاى سبك ياسخخنشخوار
}

\author{
"حميدرضا كلزار'، عبدالعزيز افلاكسير، جواد ملازاده؟ \\ 1- كارشناسى ارشد، كروه روانشناسى بالينى، دانشكده علوم ثربيتى و روانشئاسى، دانشكاه شيراز، شيراز، ايران.

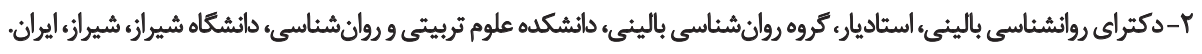

\begin{abstract}
حكند
هدف مطالعه حاضر با هدف بررسى معادلهماي ساختارى نكرش هاى ثاكار آمد با علاثم افسردكى و بررسى ثقش واسطهاي سبك باسخ نشخوار

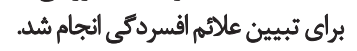

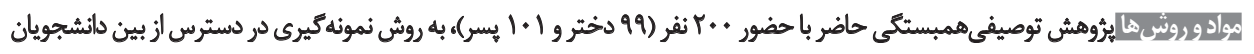

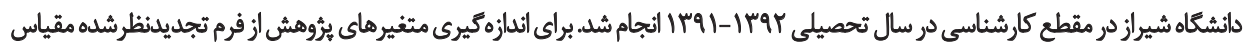

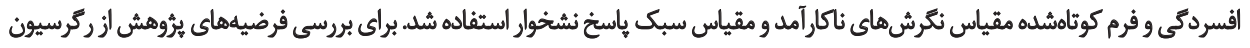

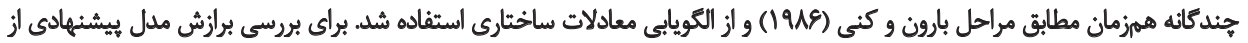

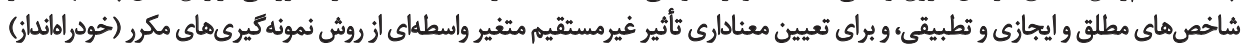

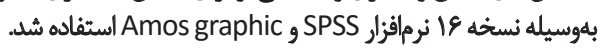

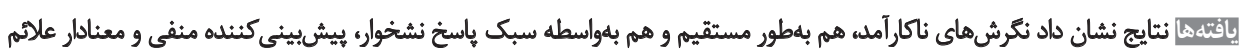

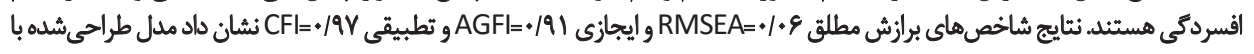

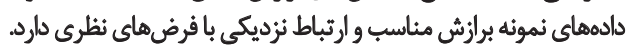

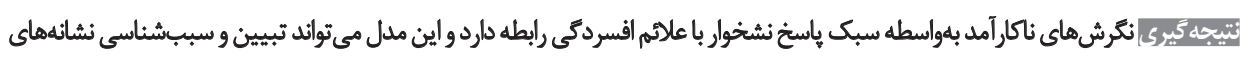
افسردكى راتسهيل كند.
\end{abstract}

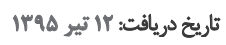

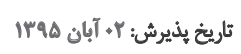

كليدوأو

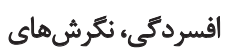

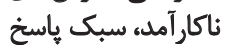
نشخوار، معادله سائ باسي ساخْتّاري

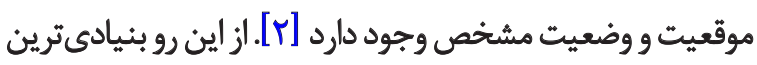

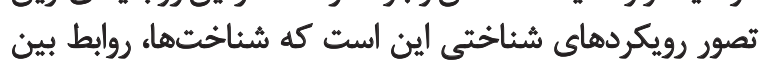

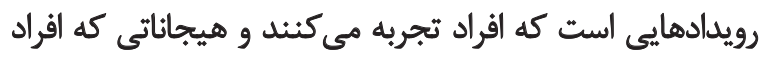

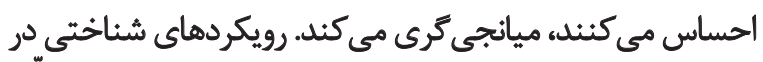

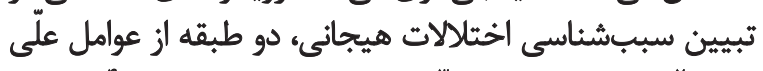

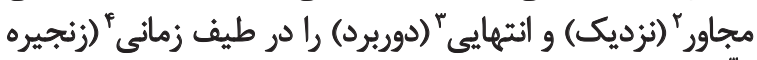

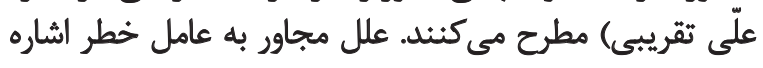

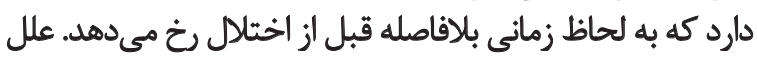

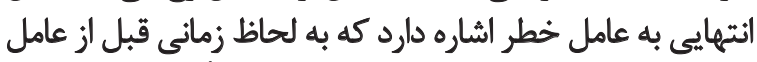

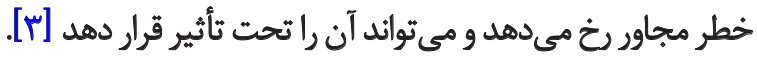

\section{Proximal factor}

3. Distal factor

4. Long-term distal- proximal continum

daleo افسردكى 'يكى از رايجترين اختلالات روانشناختى است كه

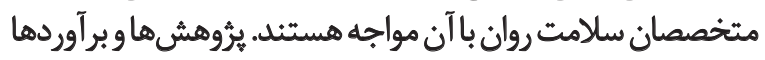

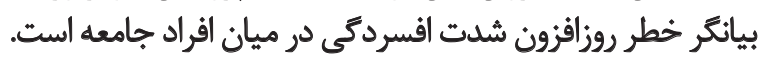

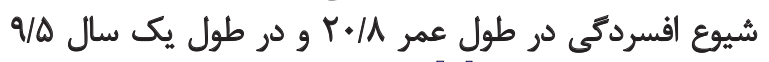

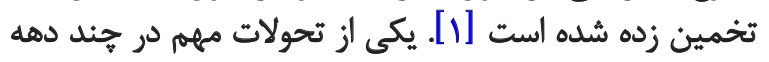

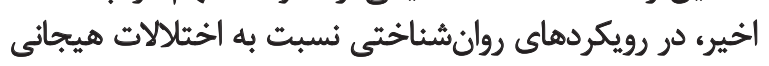

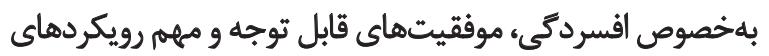

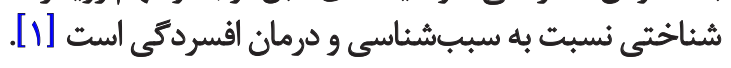

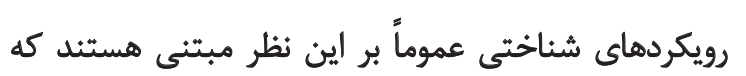

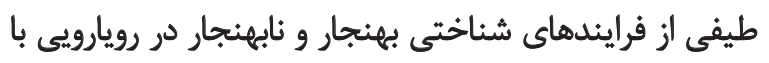

1. Depression

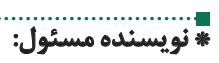

حميدرضا كلزار

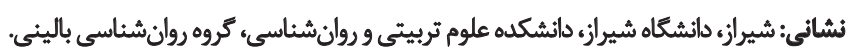

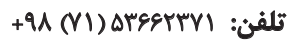
بـت بلكن الكترونيكي: hamidrezagolzar65@gmail.com 


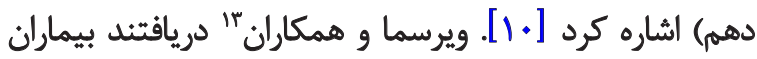

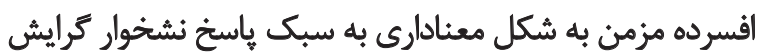

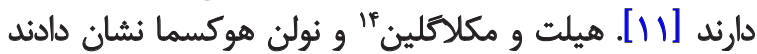

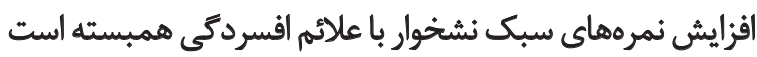

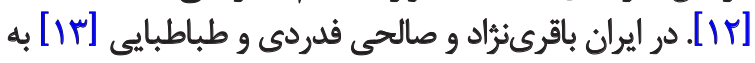

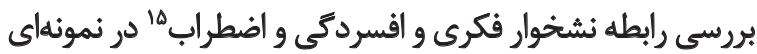

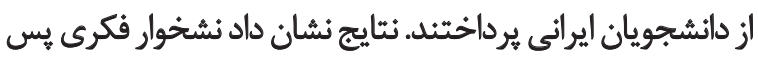

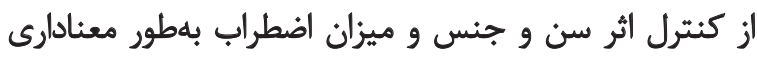
افسردگى را ييشبينى مي كند.

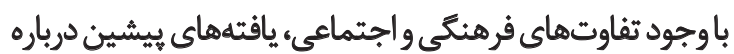

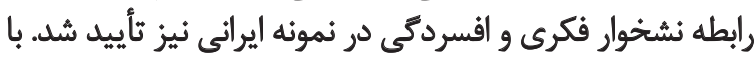

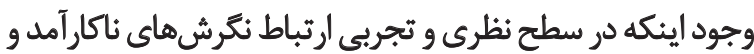

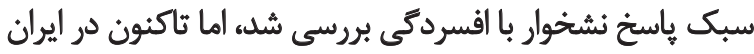

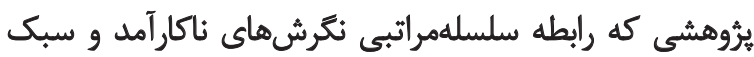

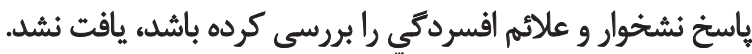

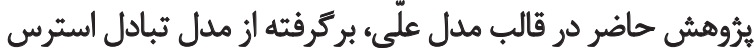

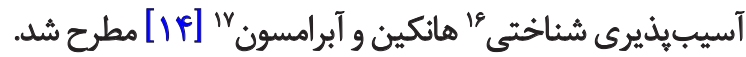

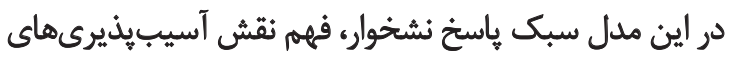

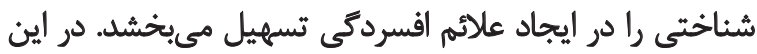

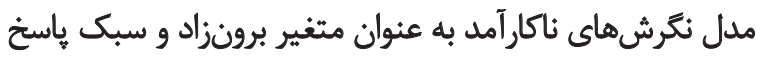

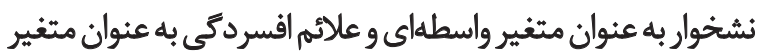

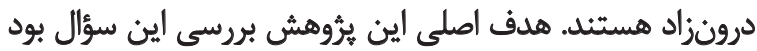

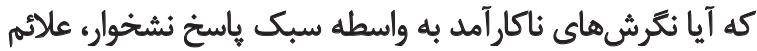

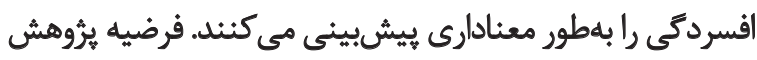

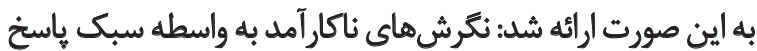

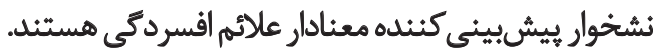

ووشي

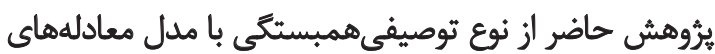

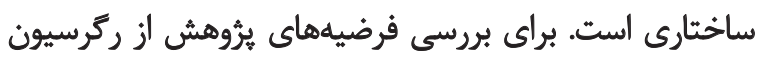

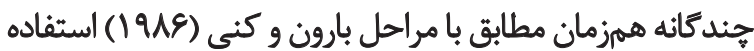

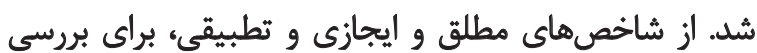

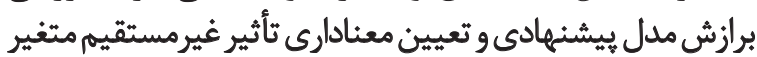

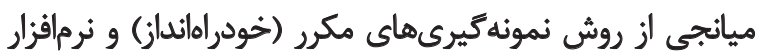

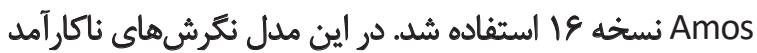

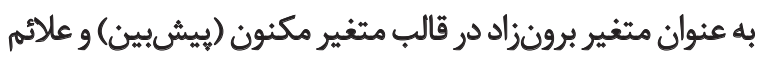

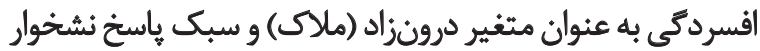
به عنوان متغير واسطهاى بررسى شدند.

13. Wiersma

14. Hilt and Mclaughlin

15. Anxiety

16. Cognitive vulnerability-transactional stress

17. Hankin and Abramson
در مدلهاى شناختى عموماً مجموعهايى از شبكههاي

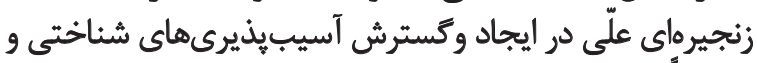

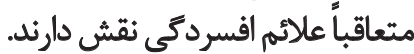

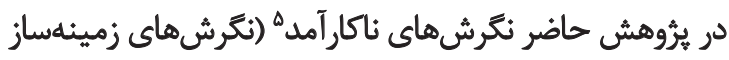

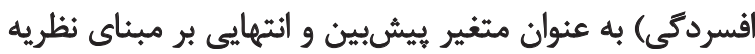

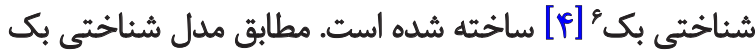

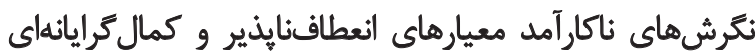

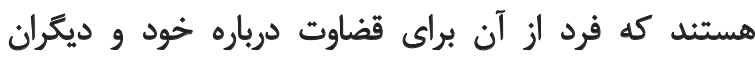

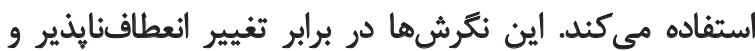

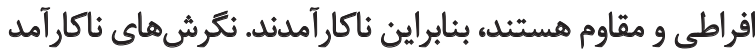

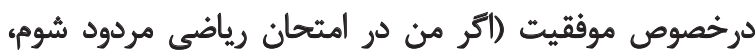

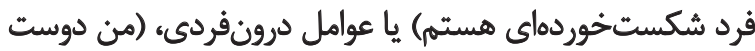

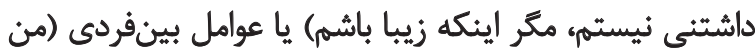

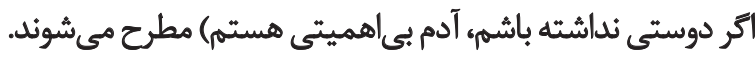
يروهشها نشان ميدهند افرادى كه سبك نتخرشهاى

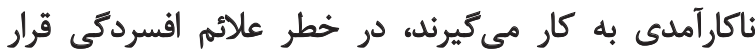

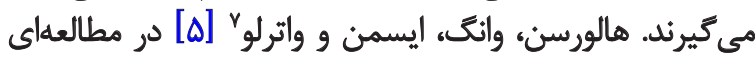

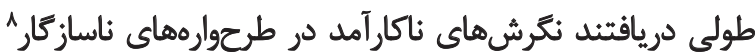

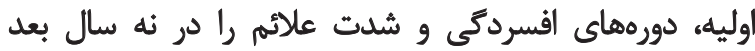

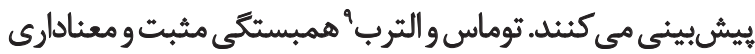

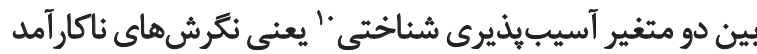

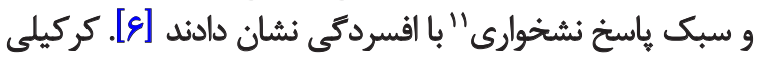

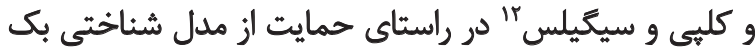

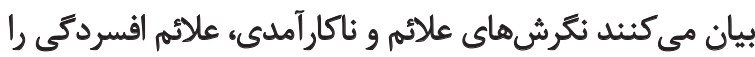

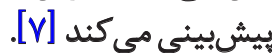

ياسخ نشخوار به عنوان متغير مجاور و ميانجيكر از نظريه

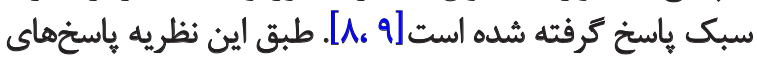

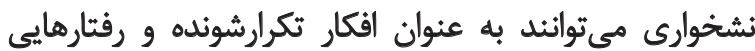

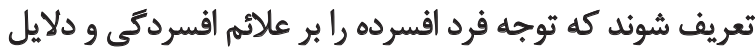

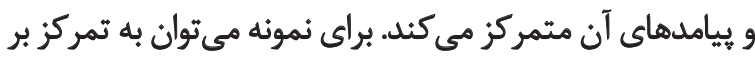

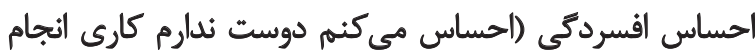

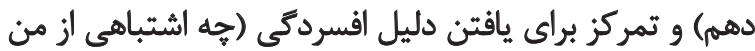

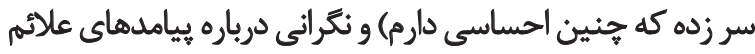

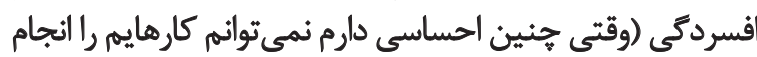

5. Dysfunctional attitudes

6. Beck

7. Halvorsen, Wang, Eisemann and Waterloo

8. Schema

9. Thomas and Altareb

10. Cognitive vulnerability

11. Ruminative response

12. Kerqeli, Kelpi and Tsigilis 


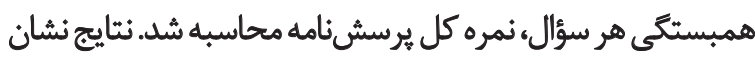

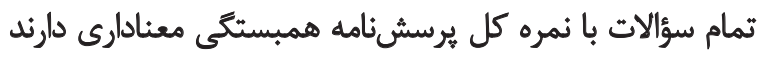

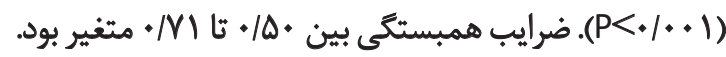

\section{مقياس نكرش شاى ناكار آمد" 19}

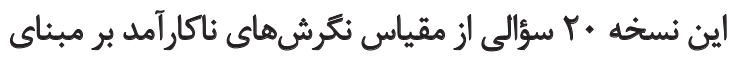

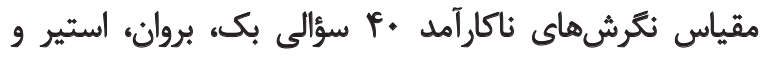

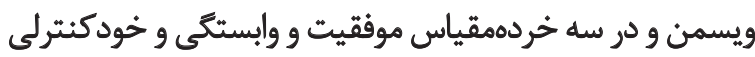

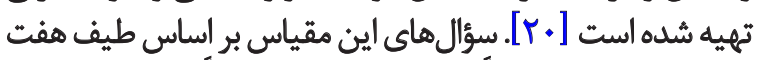

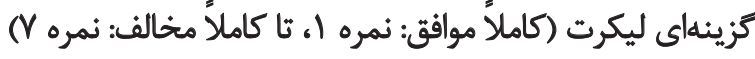

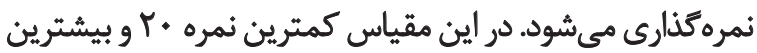

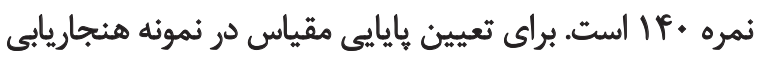

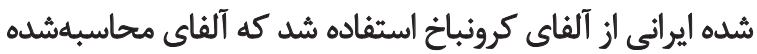

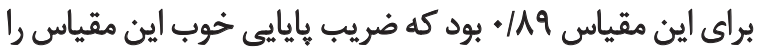

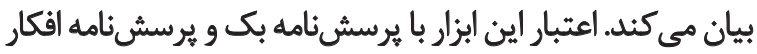

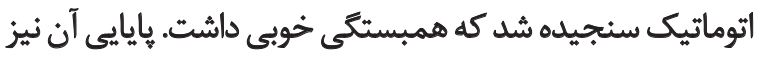
به روش آزمون مجدد بسيارخوب كزارش شد شد

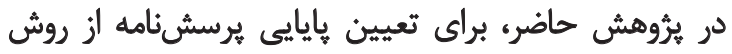

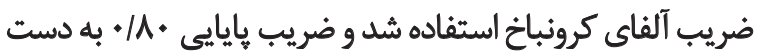

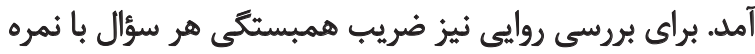

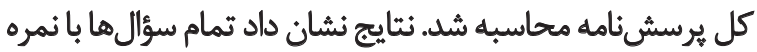

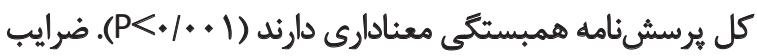

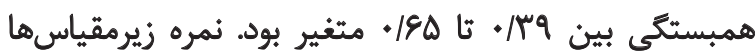

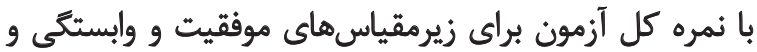

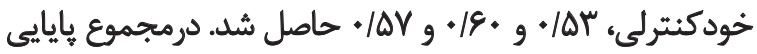

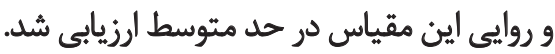

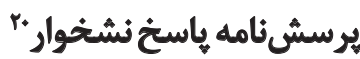

نولن هوكسما و مارو" يرسشنامهاي خودآزما تدوين كردند

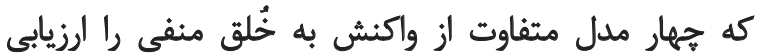

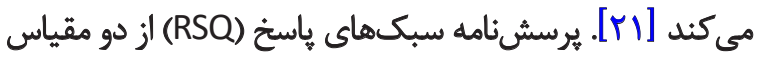

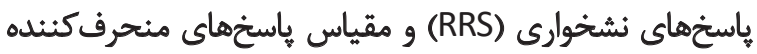

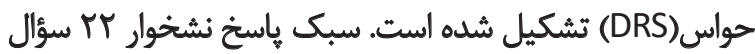

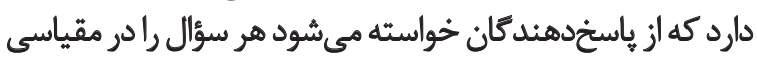

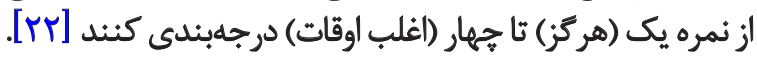

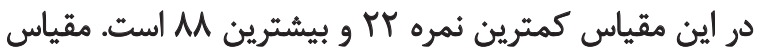

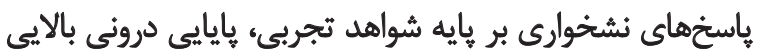

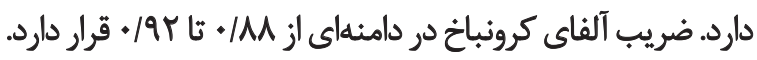

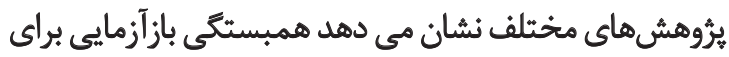

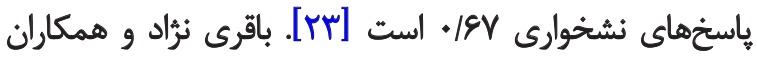

19. DAS

20. RRS

21. Morrow
جامعه آمارى اين يُروهش شامل تمام دانشجويان دانشعاه

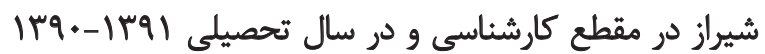

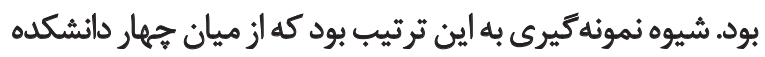

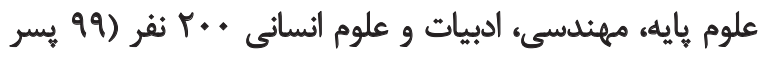

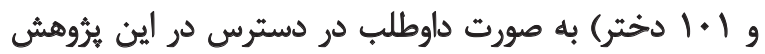

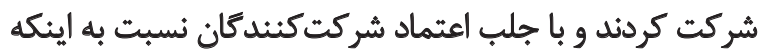

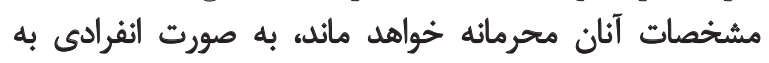

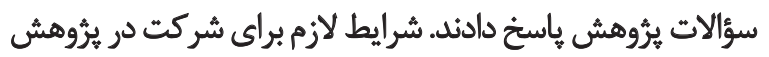

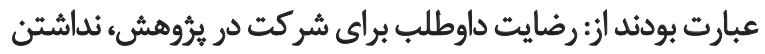

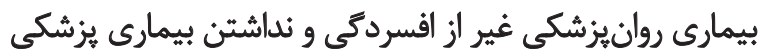

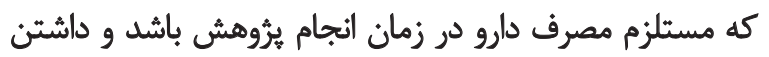

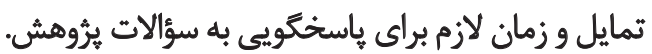
إنس از مراجعه حضورى به دانشجويان و بيان اهداف يرؤهش،

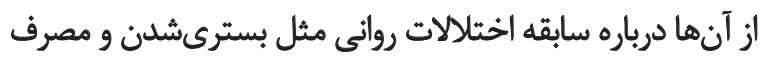

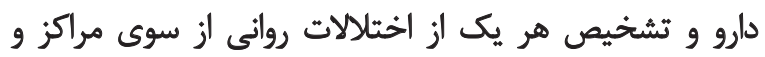

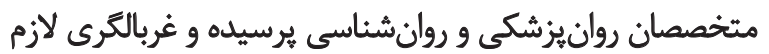

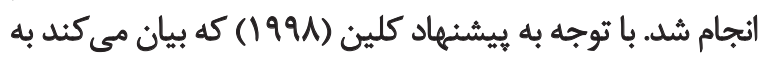

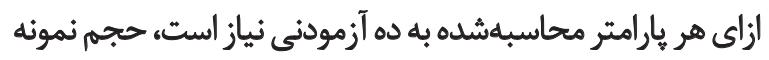

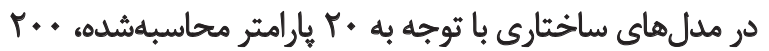

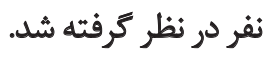

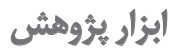

\section{يرسشنامه افسردكى بك، ويرايش دوم”"}

اين مقياس شكل بازنترى شده يرسش نامه افسردمى بك است

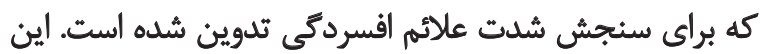

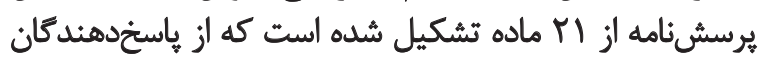

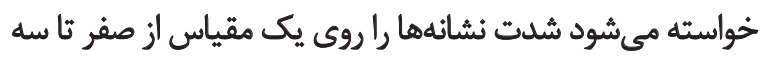

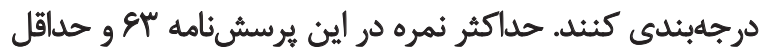

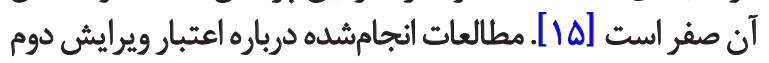

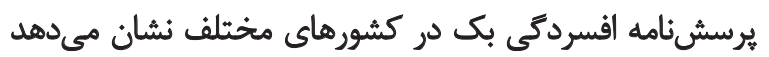

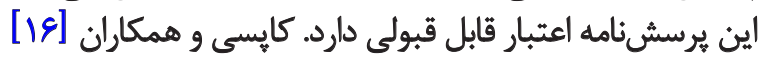

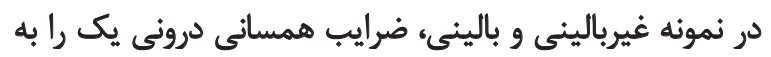

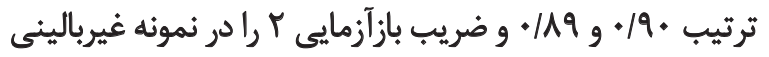

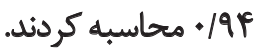

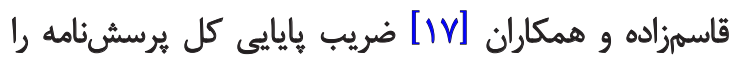

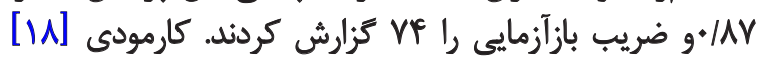

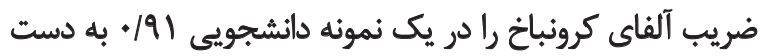

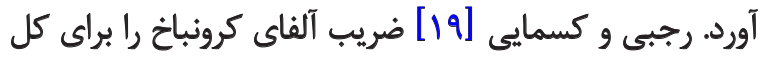

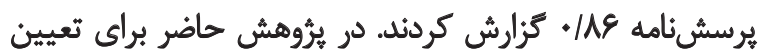

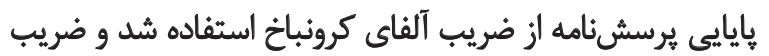

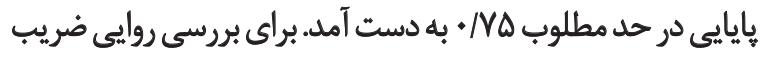

18. BDI-II 


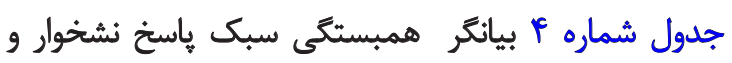

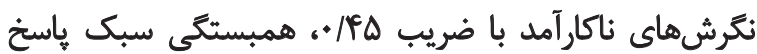

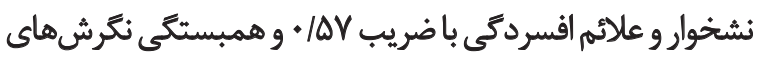

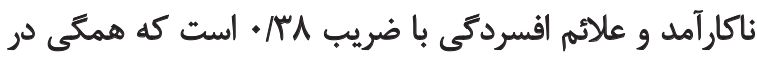

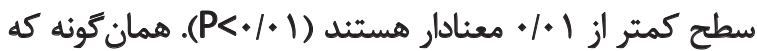

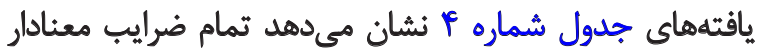

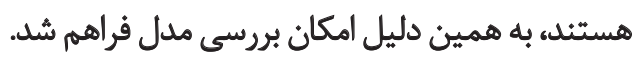

\section{تحليل مسير}

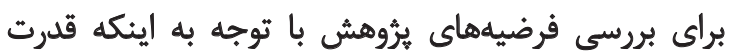

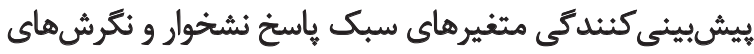

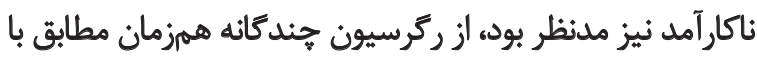

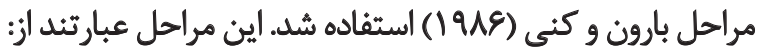

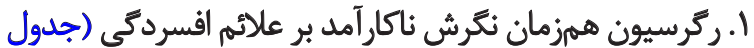

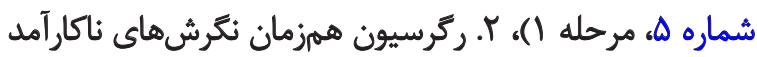

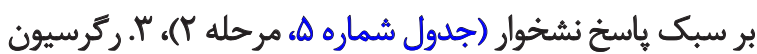

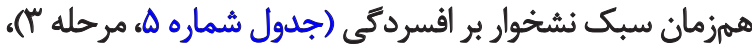

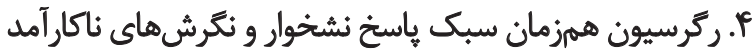

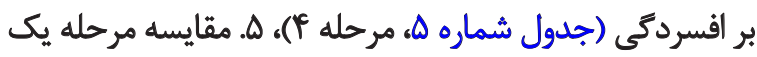

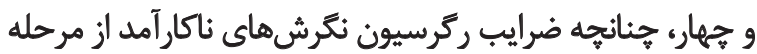

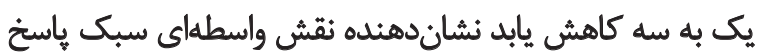

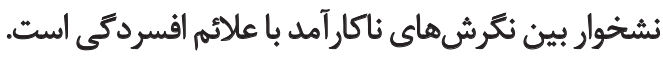

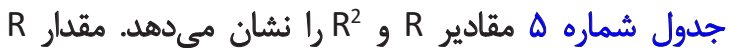

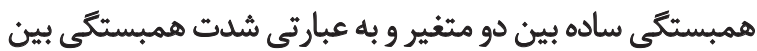

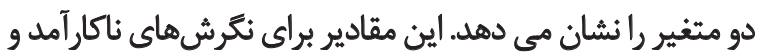

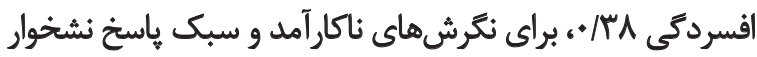

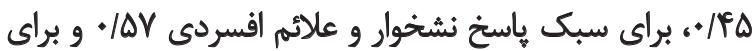

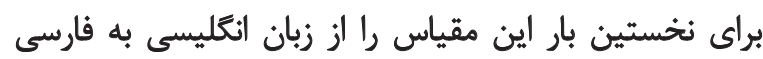

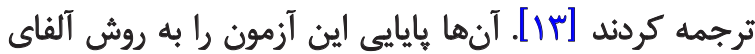

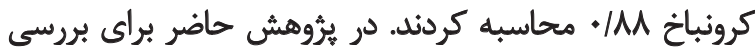

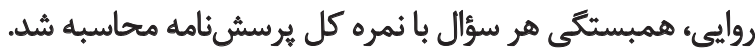

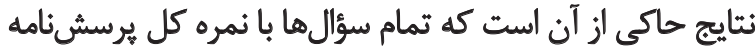

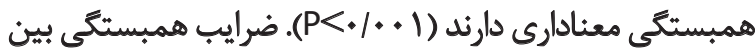

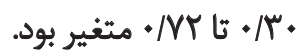

يافتهها

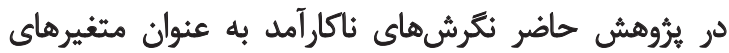

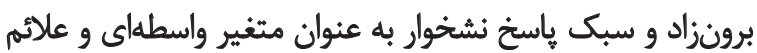

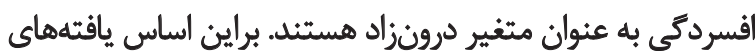

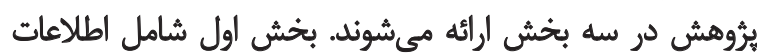

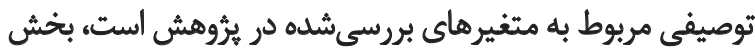

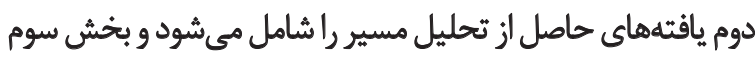

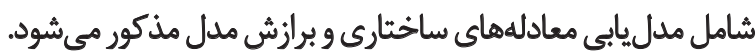
در جدول شماره 1 شاخصهاى توصيفى مربوط به سن سن

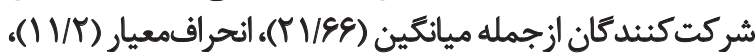

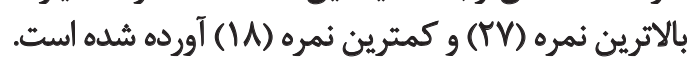

در جدول شماره Y شاخصهاى توصيفى مربوط به ميزان

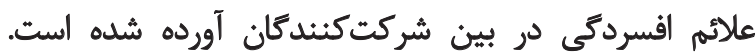

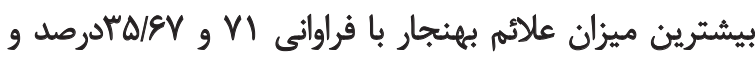

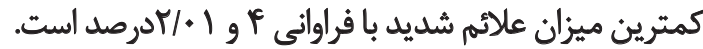

شاخصهاى توصيفى ازجمله ميانكين، انحرافمعيار، حداقل

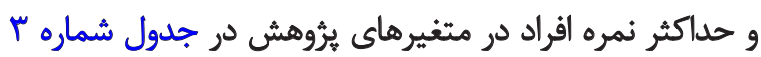
آور ده شده اسث.

جدول ا. شاخصهاى توصيفى مربوط به سن شركت كثندكان.

\begin{tabular}{|c|c|c|c|c|c|}
\hline تعداد & كمترين نمره & بالاترين نمره & انحرافمعيار & مياتكين & متغير \\
\hline$r .$. & M & r & $11 / \pi$ & ryeg & سن \\
\hline
\end{tabular}

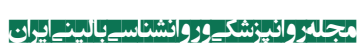

جدول r. شاخص هاى توصيفى مربوط به ميزان علاثم افسردكى شركت كنيدكان بر اساس نمره برسشنامه افسردكى بك.

\begin{tabular}{|c|c|c|}
\hline درصد & فراوانى & ميزان الفسردكّ \\
\hline$r \Delta / \& V$ & $n$ & بهنجار \\
\hline $\mathrm{rV} / \mathrm{M}$ & $n^{e}$ & خُفيف \\
\hline$r \Delta / I r$ & $\Delta$. & متونسط \\
\hline$r / \bullet 1$ & $p$ & شديد \\
\hline $1+$. & 199 & كل \\
\hline
\end{tabular}

كجلم: 
جدول ب. شاخص هاى توصيفى متغيرهاى ثيروهش.

\begin{tabular}{|c|c|c|c|c|}
\hline تعداد & حداكثر نمره & حداقل نمره & مياتئين (انحراقمعيار) & مثغيرها \\
\hline$r+$. & $1 \Delta F$ & re & $\| \triangle / T N(\mid \& / \cdot V)$ & نكرش شاى ناكارآمد \\
\hline Y.. & A. & rq & $\Delta I / / \Delta\left(1 Y /+\varphi^{e}\right)$ & سبك ياسنخ ثشخوار \\
\hline$r+$. & $\Delta \wedge$ & $\cdots$ & IV/AA(IY/AF) & علائم اقسردكى \\
\hline
\end{tabular}

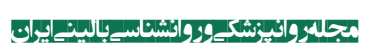

جدول F. مائريس همبستَّى متغيرهاى يُّوهش.

\begin{tabular}{|c|c|c|c|}
\hline$r$ & r & 1 & متغيرها \\
\hline & & 1 & نكرشهاي ناكارآمد \\
\hline & 1 & $* / F \theta^{* * *}$ & سبك باسيخ نشخوار \\
\hline 1 & $\cdot / \Delta V^{* *}$ &.$/ \Lambda^{* * *}$ & علائم افسردمى \\
\hline
\end{tabular}

با سبك ياسخ نشخوار با كاهش ضريب بثا در مثايسه با مرحله

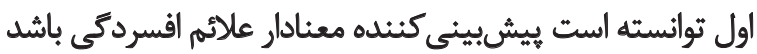

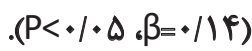

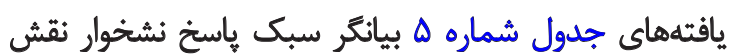

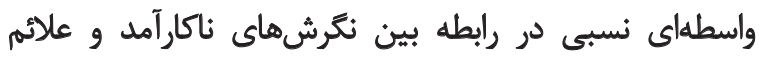
افسردكى است. يثوهش حاضر به دنبال ياسخ به ائ اين سؤال بوده

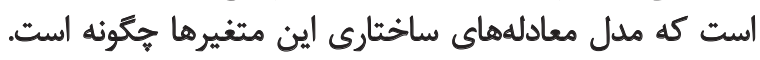

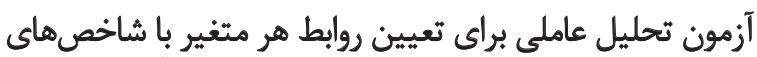

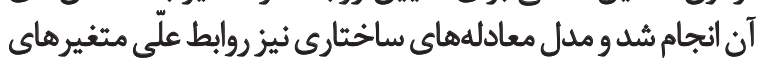

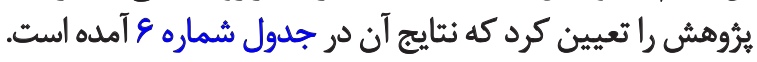

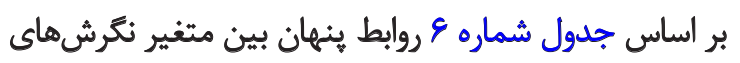

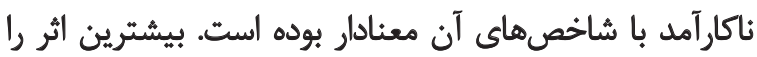

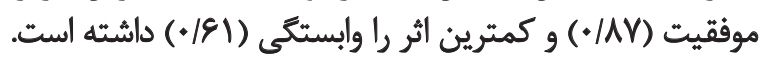

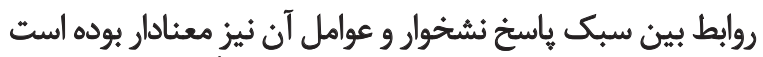

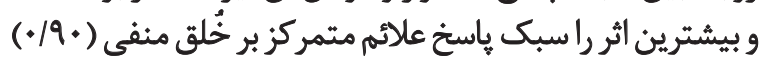

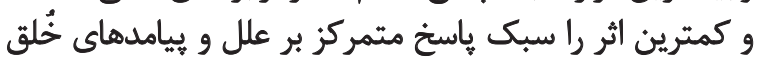

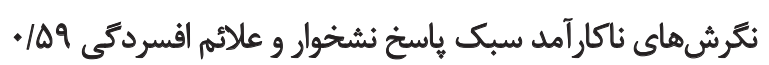

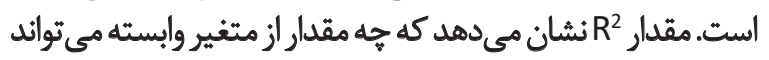

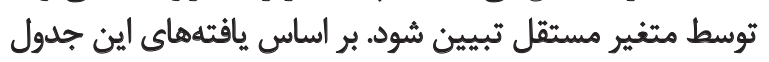

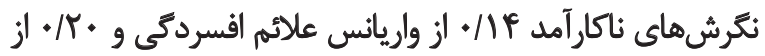

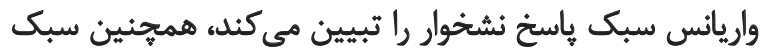

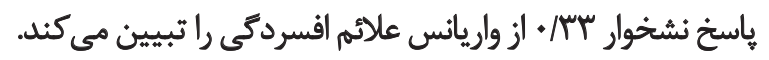
در مرحله جههار نغرشهاى ناكارآمد و سبك ياسخ نشخوار

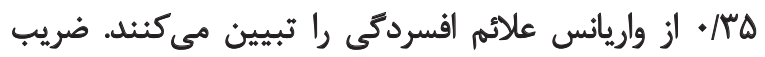

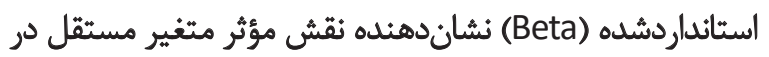

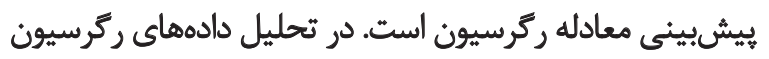

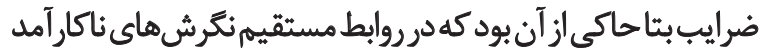

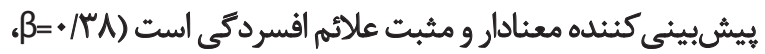

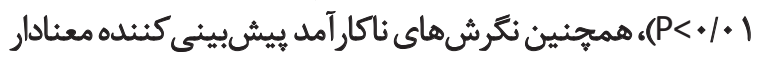

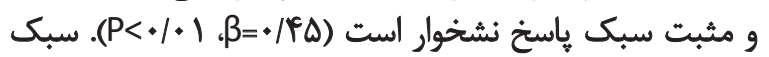

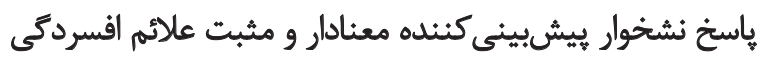

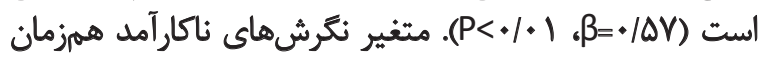

جدول ه. ركرسيون همزمان متغيرهاى نكرش هاى ناكار آمد و سبك باسخ نشخوار بر افسردكى.

\begin{tabular}{|c|c|c|c|c|c|c|c|}
\hline سطح معنادارى & $\beta$ & B & $\mathrm{R}^{2}$ & $\mathbf{R}$ & مثغير مالى & متغير ويشيين & مرحله \\
\hline$<\cdot 1+1$ & $\cdot / \pi$ & $\cdot / \mu$ &.$/ 1 F$ &.$/ \pi \Lambda$ & عالائم اقسردكى & نكرش هاى ناكارآمد & 1 \\
\hline$<\cdot 1 \cdot 1$ &.$/ 160$ & . I I I & $\cdot \pi$ &.$/ \% \Delta$ & سبك ياسِخ نشختوار & نكرش شالى ناكارآمد & r \\
\hline$<. / .1$ & $\cdot / \Delta V$ & $.18 V$ & - & $\cdot / \Delta Y$ & عالائم افسردكى & سبكياسنخ نشخوار & r \\
\hline $\begin{array}{l}<\cdot / \cdot \infty \\
<\cdot / * 1\end{array}$ & $\begin{array}{l}. / 1 f \\
. / 01\end{array}$ & $\begin{array}{l}.111 \\
.109\end{array}$ & . &.$/ 09$ & عالاثم افسردمى & نكبرش هاى ناكارآمد & p \\
\hline
\end{tabular}

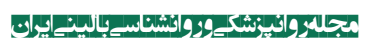


جدول \&. روابط بين متغيرهاي يُّوهش و شاخصهاي آنها.

\begin{tabular}{|c|c|c|c|c|c|}
\hline \multicolumn{6}{|c|}{ تأثير اسثاندارد مسثقيم متغير هاى مدل بئوهش } \\
\hline سطح معنادارى & أنحر اف اسثياندارد & سبكياسخ نشخوار & نكرش نهاى ناكارآمد & علائم افسردكى & متغيرها \\
\hline$\cdot 1 \cdot+1$ & $.1+1$ & 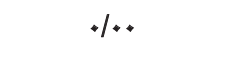 & $+1 *$ & $\cdot \operatorname{lN}$ & شناختي \\
\hline .1 .01 & .1 .1 & $\%$ & $\cdots$ & .119 & رف رفتارى \\
\hline $.1 \cdot .1$ & .1 .8 &. & $\cdots$ & $\cdot|A|$ & 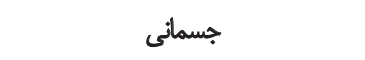 \\
\hline $.1+.1$ & .119 &. & $\cdot / \mathrm{AV}$ & $\%$ & موققيت \\
\hline $.1 * 1$ &.$/ 14$ & 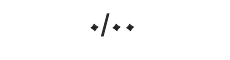 &.$|8|$ & .1. & وابستكى \\
\hline $.1++1$ & .110 & 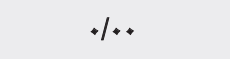 & .198 & $\%$ & 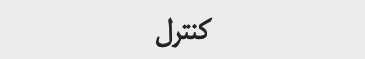 \\
\hline $.1 \cdot+1$ &.$/ 1 \%$ & .19 & 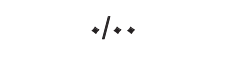 & 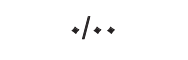 & مإسخ متمركز بر علائم \\
\hline$+1++1$ & .11 & $\cdot / A F$ & $+1+$ & $+1+$ & ياسخخ متمركز بر خود \\
\hline .10 .1 & .108 & $\cdot M^{e}$ & .10 & .1. & ياسيخ متهركز بر علل و ويامدهاي خُلق \\
\hline
\end{tabular}

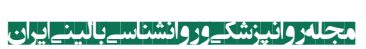

نشخوار (هو •) است (جدول شماره V). به اين ترتيب مىتوان

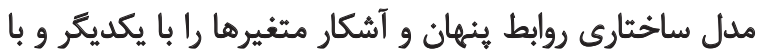

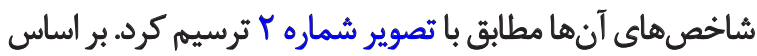

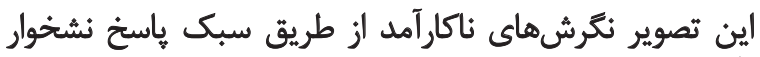

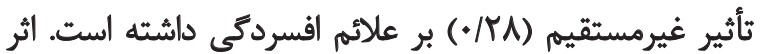

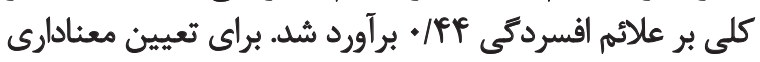

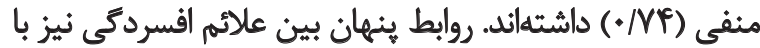

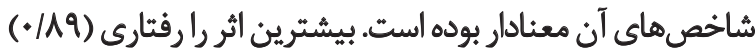

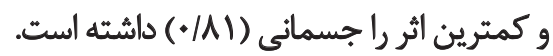
متغيرهاى بروهش بر علائم افسردگى تأثير مستقيم داشتهاند

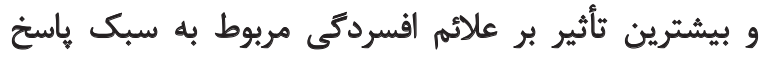

جدول V. ورابط بين متغيرهاى بروهش بر حسب مدل معادلهماي ساختّارى.

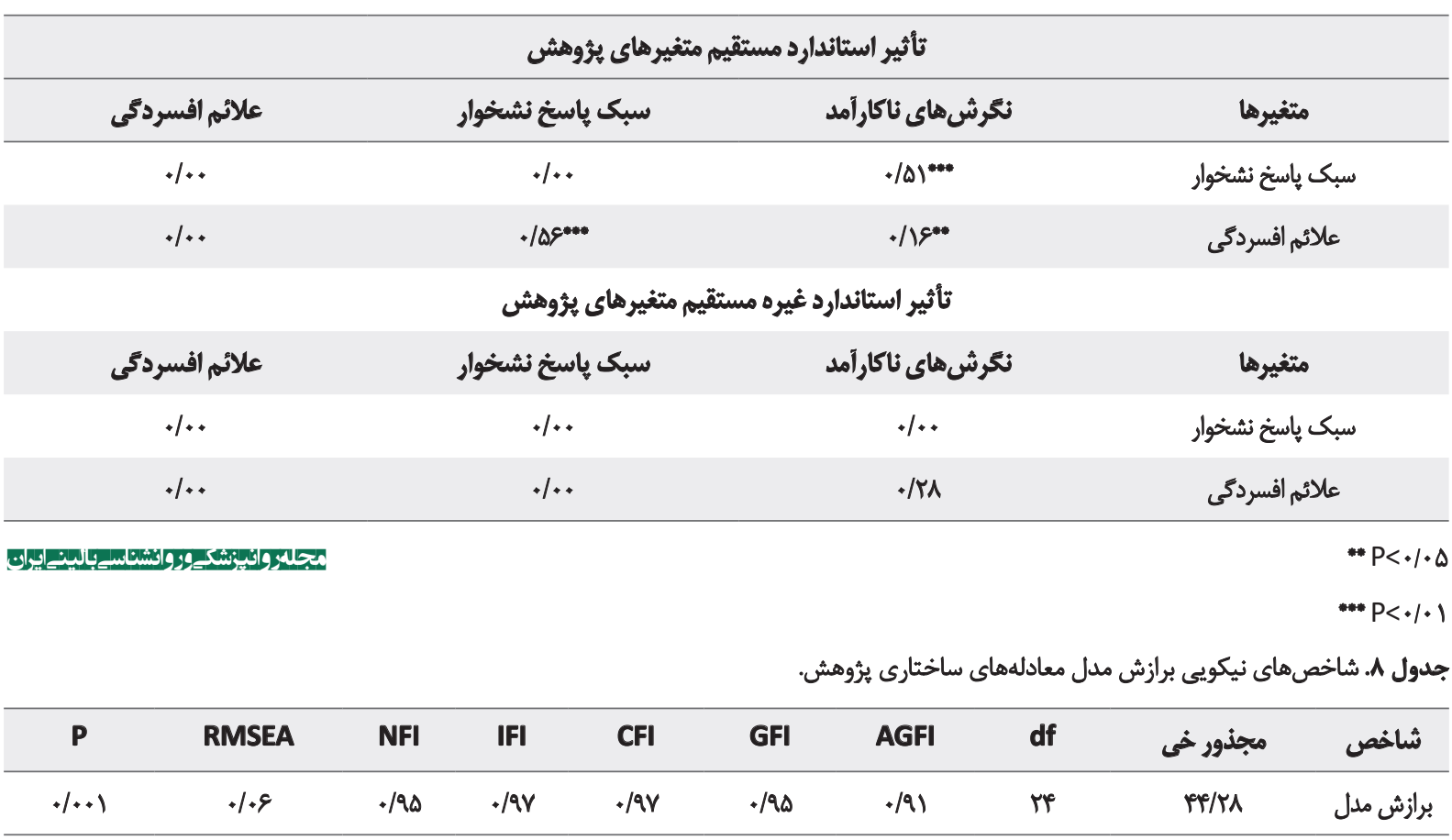

كحلd 


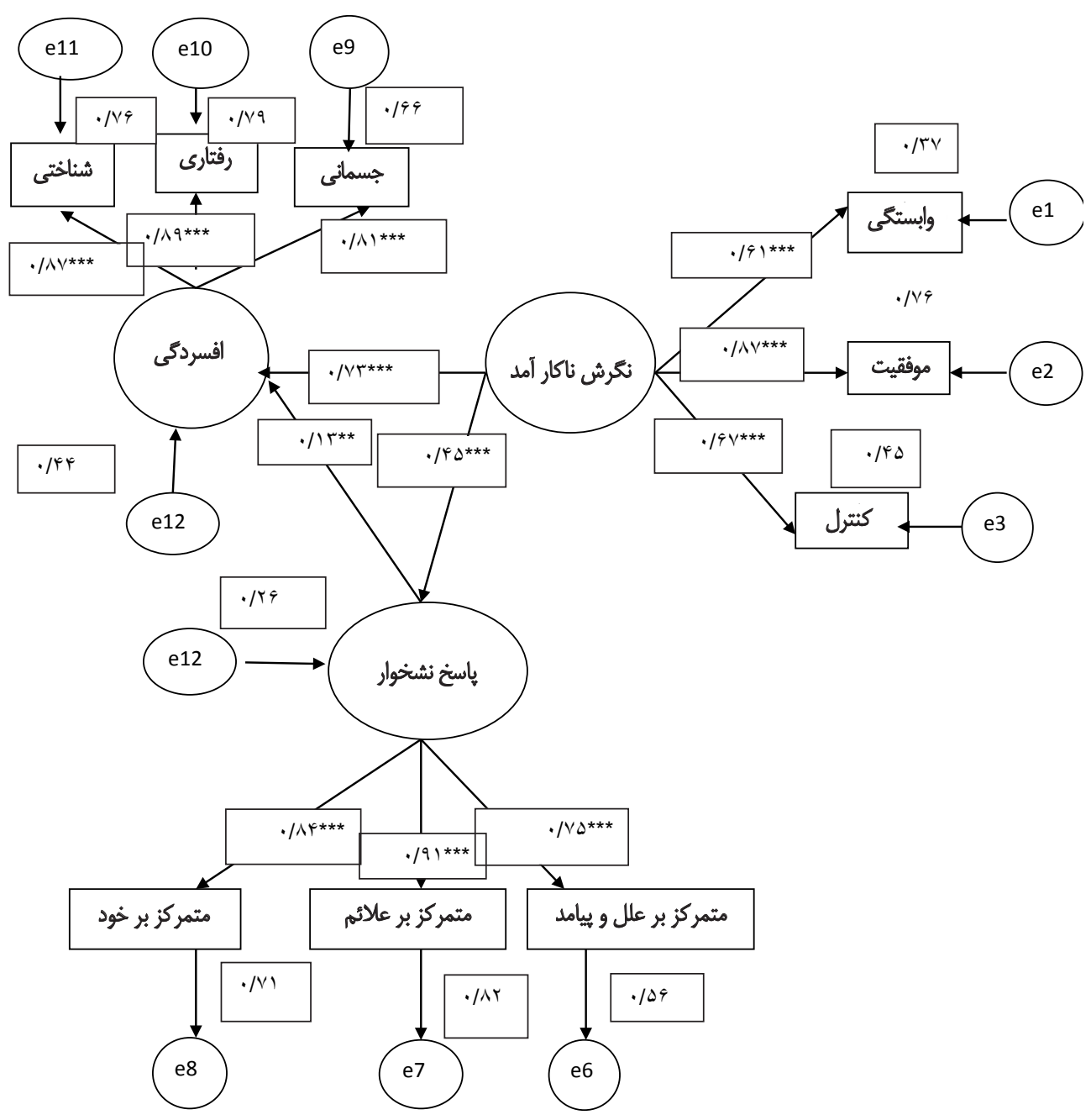

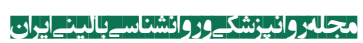

$$
\begin{aligned}
& \text { تصوير r. مسيرهاى مدل. } \\
& \text { ** } P<+1+\Delta \\
& \text { *** } P<.1 .1
\end{aligned}
$$

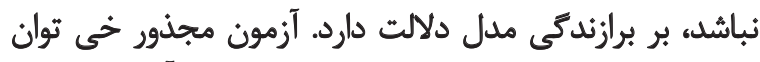

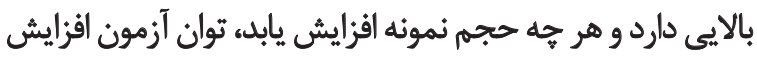

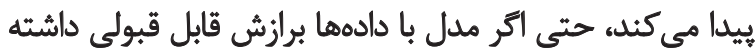

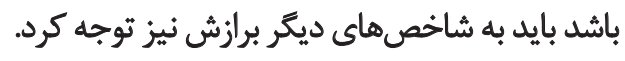

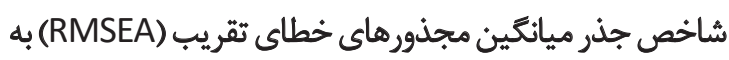

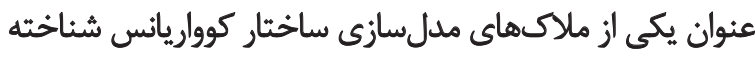

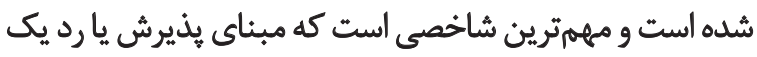

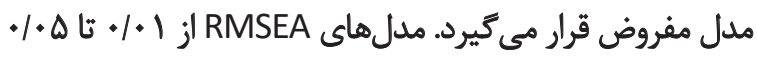

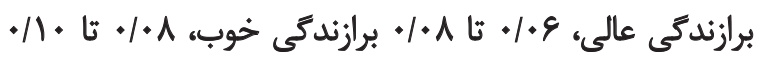

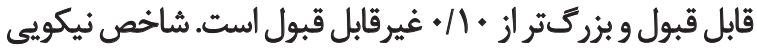

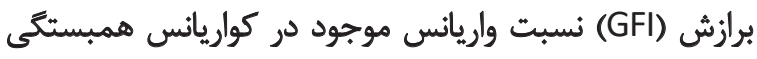

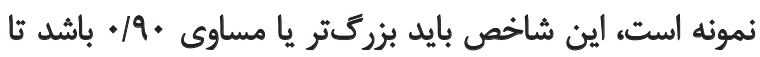

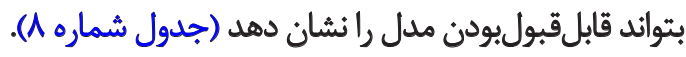

اثر غيرمستقيم متغير واسطهاى از روش نمونهكيرىهاى مكري

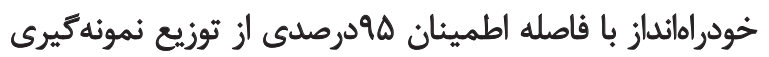

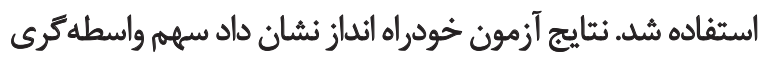

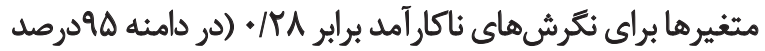

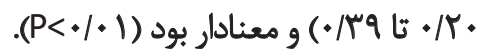

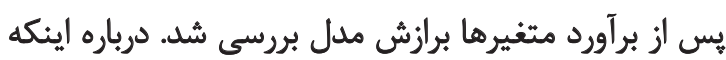

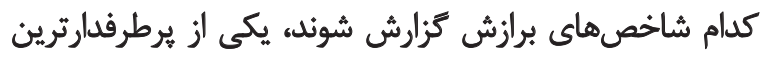

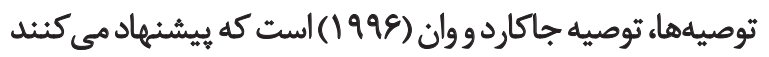

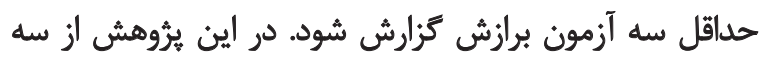

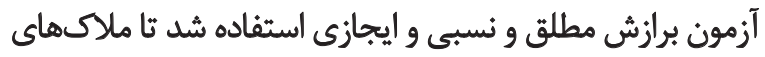

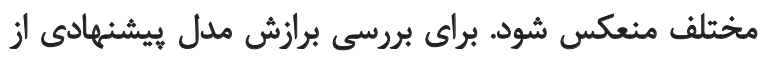

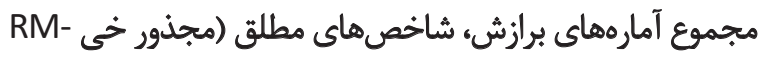

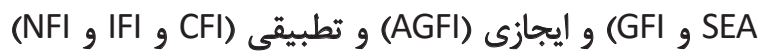
اندازهكيرى شد. اكر آزمون مجذور خى از لحاظ آمارى معنادار 


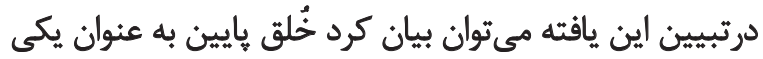

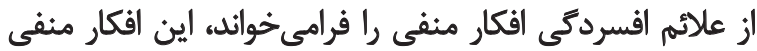

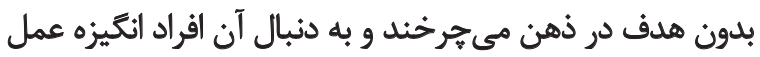

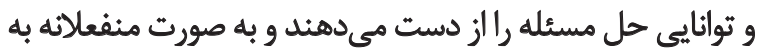

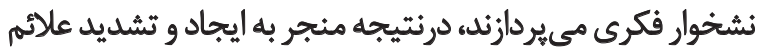

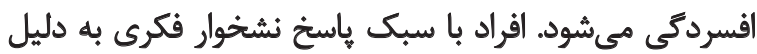

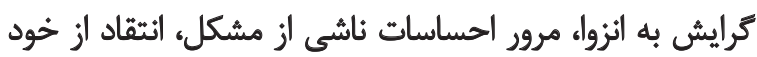

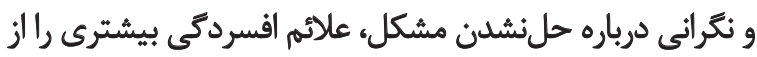

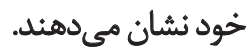

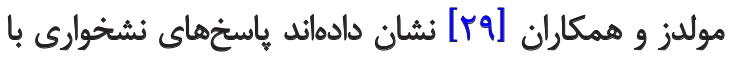

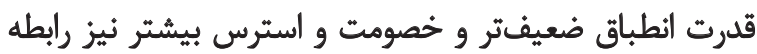

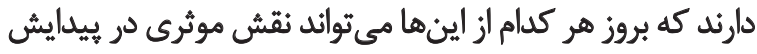

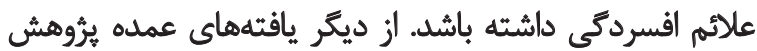

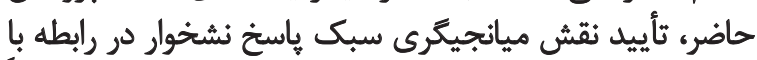

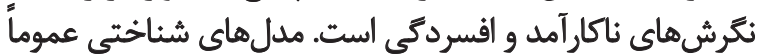

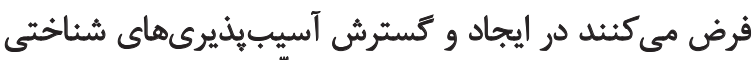

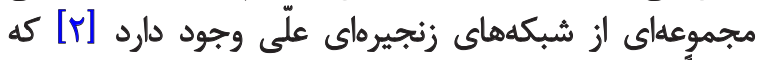

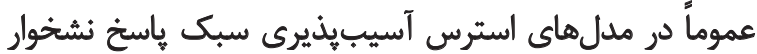

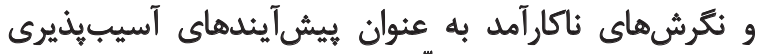
شناختى در شبكه زنجيره علّى علائم افسردى بـى مطرح هستئد.

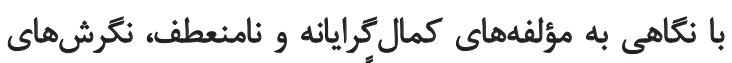

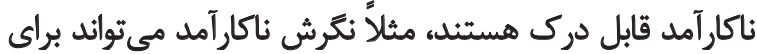

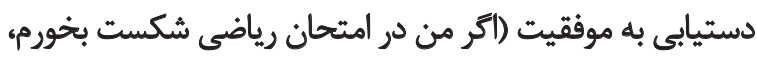

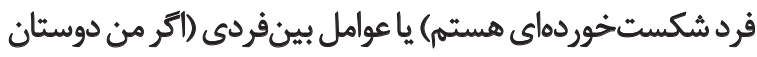

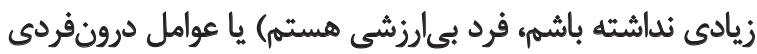
(آكر من تناسب اندام خوبى نداشته باشم، ناشايست هستم) باشد.

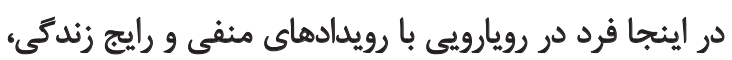

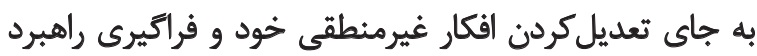

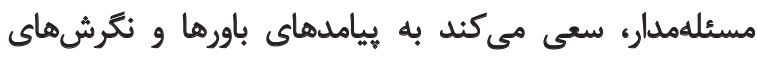

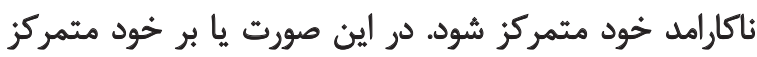

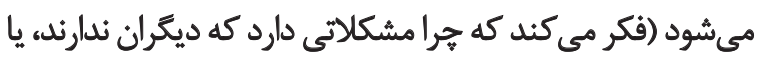

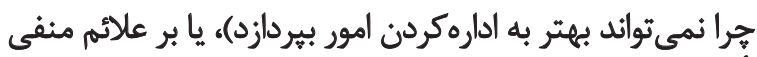

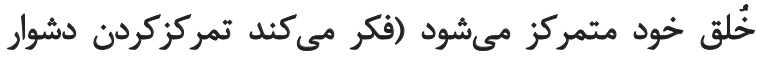

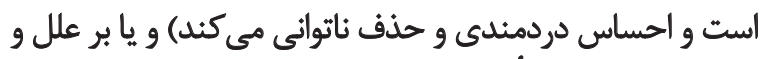

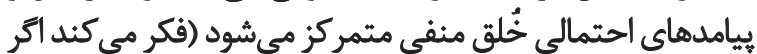

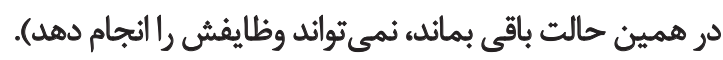
حذف اينها موجب انزواى بيشتر فرد، انتقاد از خودي، مرور

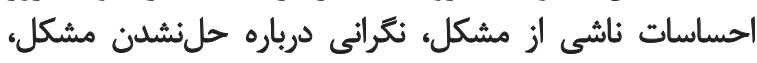

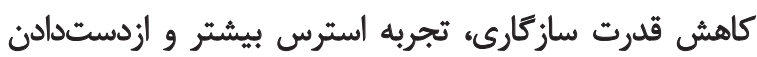

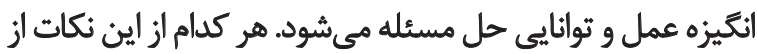

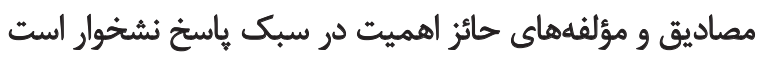

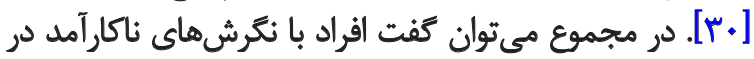

بايرن (1991) در شاخص برازش مقايسهاى (CFI) بيشنهاد

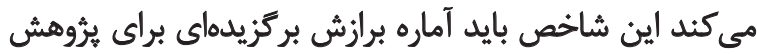

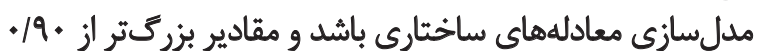

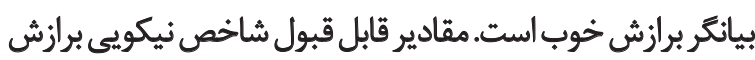

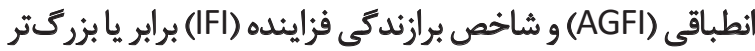

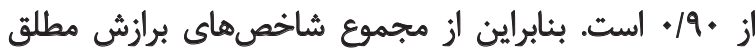

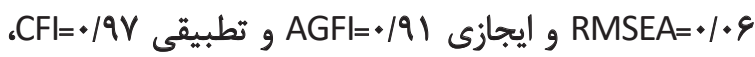

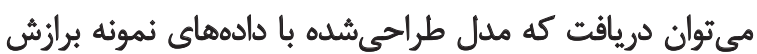

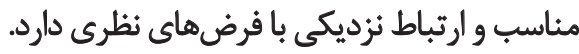

بحث

هدف از يثروهش حاضر بررسى شدت علائم افسردكى در قالب

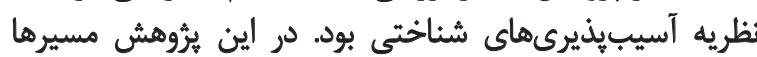

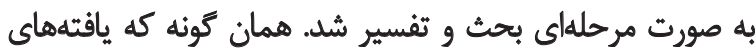

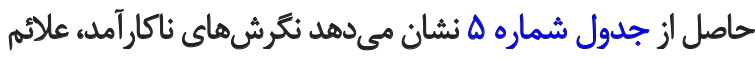

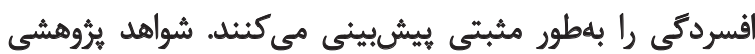

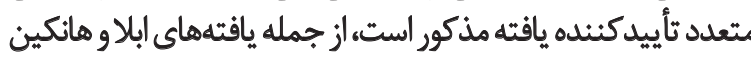

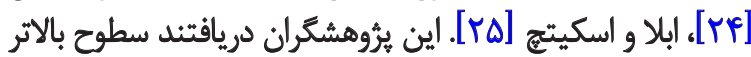

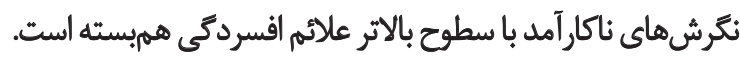

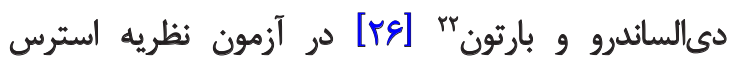

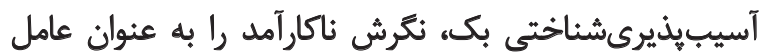

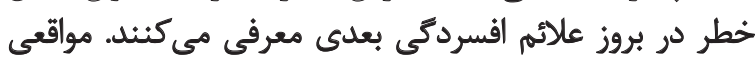

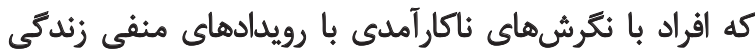

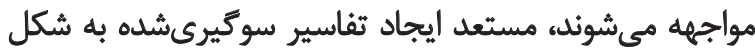

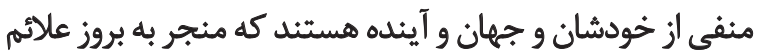

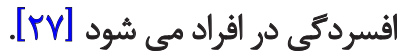

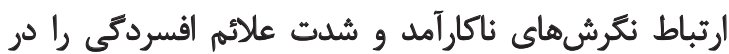

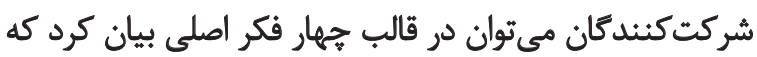

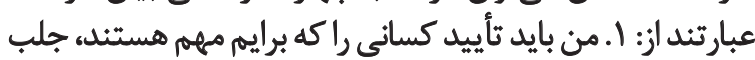

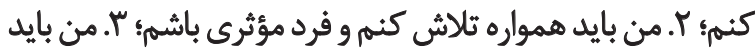

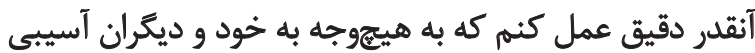

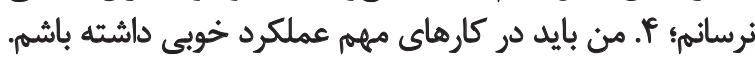

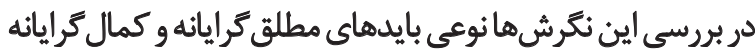

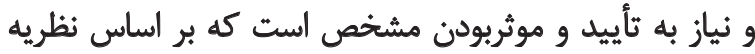

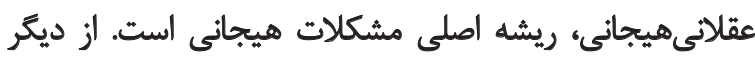

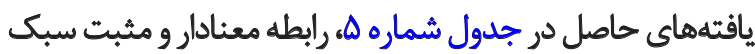
باسخ نشخوار بر شدت علائم افسردكى است.

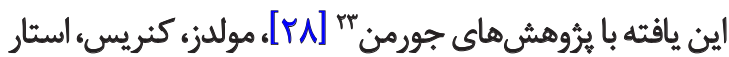

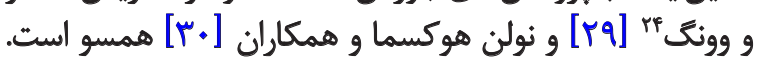

22. D.Alessandro and Burton

23. Joormann

24. Moulds, Kandris, Star and Wong 


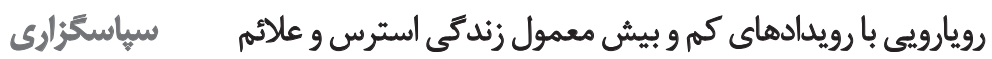

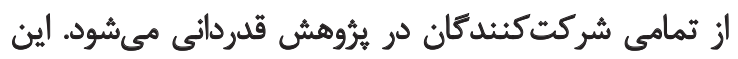

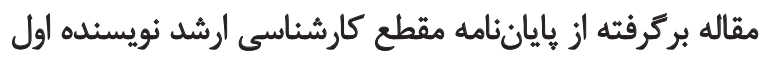

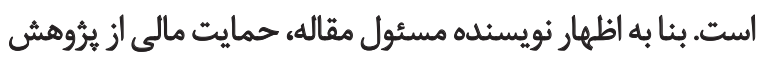
و ت تعارض منافع وجود نداشته است.

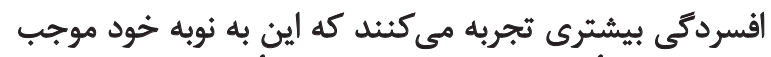

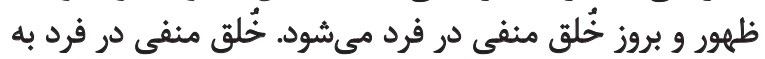

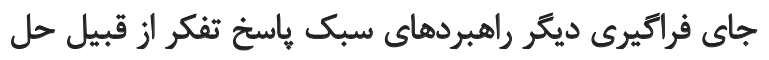

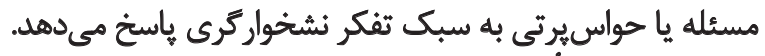

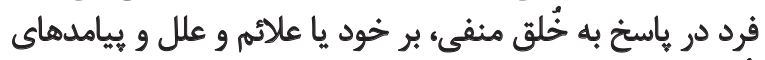

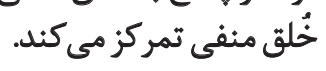

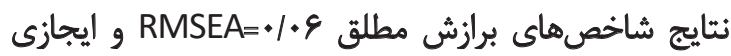
باد AGFI=•/91

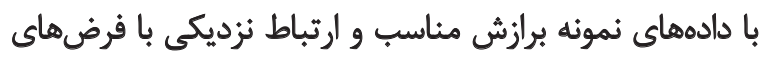

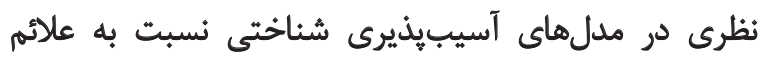

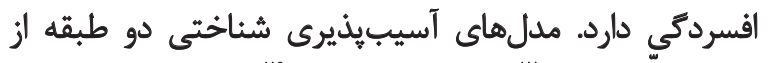

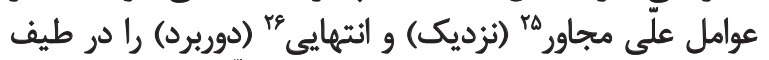

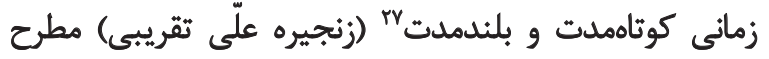

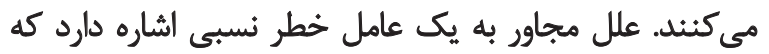

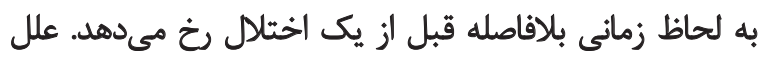

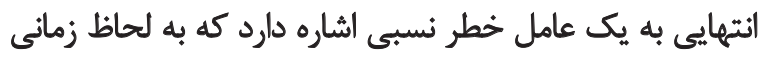

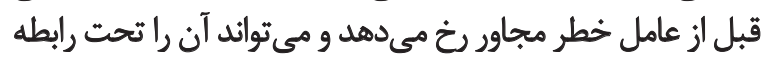

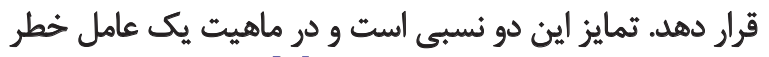

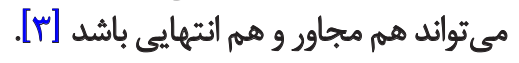

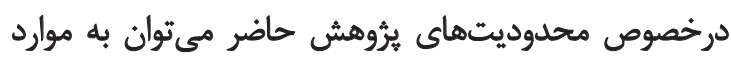

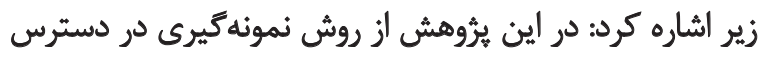

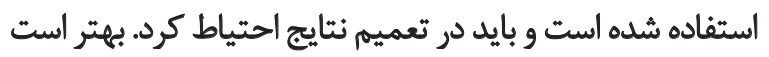

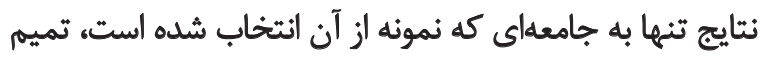

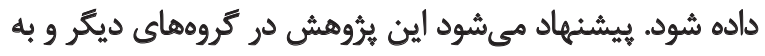

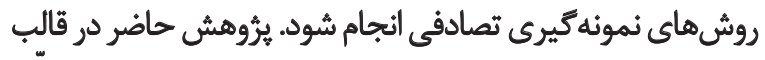

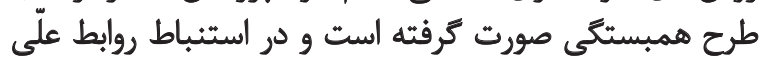

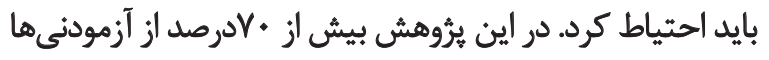

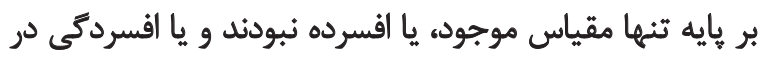

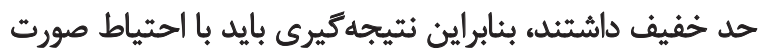

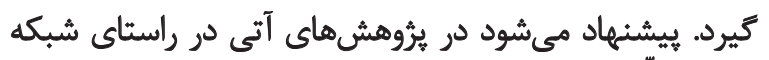

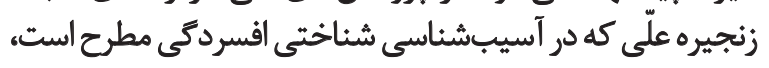

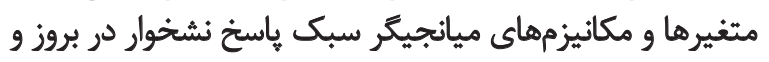
شدت علائم افسردمى شناسايى شود. نتيجليَّيرى

نتايج اين مطالعه بيانكر نقش واسطهاى سبك ياسخ نشخوار

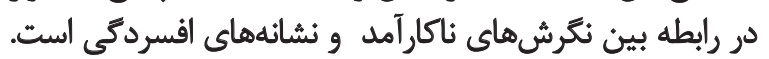

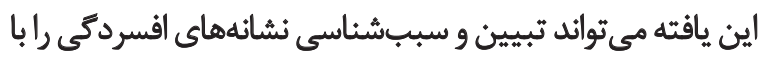

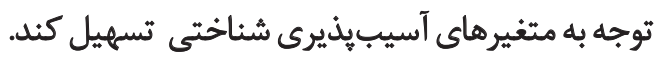




\section{References}

[1] Barlow DA. Clinical handbook of psychological disorders: A step-by-step treatment manual. New York: Guilford Publications Inc.; 2006.

[2] Riskind JH, Alloy LB. The cognitive vulnerability to depression (CVD) Project: Current findings and future directions. In Alloy LB, Rishkind JH, editors. Cognitive Vulnerability to Emotional Disorders. New Jersey: Paulist Press; 2006.

[3] Ingram RE, Atchley RA, Segal ZV. Vulnerability to depression: From cognitive neuroscience to prevention and treatment. New York: Guilford Publications Inc.; 2011.

[4] Kooshki S, Jamali M, Salehi M, Akbari H. [The effectiveness of stress reduction strategies based on mindfulness and dysfunction attitudes in a group of patients with heart disease (Persian)]. Psychol Studies. 2012; 15(4):93-112.

[5] Halvorsen M, Wang CE, Eisemann M, Waterloo K. Dysfunctional attitudes and early maladaptive schemas as predictors of depression: A 9-year follow-up study. Cognitive Therapy \& Research. 2009; 34(4):368-79. doi: 10.1007/ s10608-009-9259-5

[6] Thomas J, Altareb B. Cognitive vulnerability to depression: An exploration of dysfunctional attitudes and ruminative response styles in the United Arab Emirates. Psychology \& Psychotherapy: Theory, Research \& Practice. 2011; 85(1):117-21. doi: 10.1111/j.2044-8341.2011.02015.x

[7] Kërqeli A, Kelpi M, Tsigilis N. Dysfunctional attitudes and their effect on depression. Procedia - Social \& Behavioral Sciences. 2013; 84:196-204. doi: 10.1016/j.sbspro.2013.06.534

[8] Nolen-Hoeksema S. Sex differences in unipolar depression: Evidence and theory. Psychological Bulletin. 1987; 101(2):259-82. doi: 10.1037/0033-2909.101.2.259

[9] Nolen-Hoeksema S. Responses to depression and their effects on the duration of depressive episodes. Journal of $\mathrm{Ab}$ normal Psychology. 1991; 100(4):569-82. doi: 10.1037/0021843x.100.4.569

[10] Nolen-Hoeksema S, Morrow J, Fredrickson BL. Response styles and the duration of episodes of depressed mood. Journal of Abnormal Psychology. 1993;102(1):20-28. doi: 10.1037/0021-843x.102.1.20

[11] Wiersma JE, van Oppen P, van Schaik DJF, van der Does AJW, Beekman ATF, Penninx BWJH. Psychological Characteristics of Chronic Depression. Journal of Clinical Psychiatry. 2011; 72(3):288-94. doi: 10.4088/jcp.09m05735blu

[12] Hilt LM, McLaughlin KA, Nolen-Hoeksema S. Examination of the response styles theory in a community sample of young adolescents. Journal of Abnormal Child Psychology. 2010; 38(4):545-56. doi: 10.1007/s10802-009-9384-3

[13] Bagherinezhad M, Salehi Fadradi J, Tabataba'i M. [The relationship between rumination and depression in a sample of Iranian students (Persian)]. Studies in Education \& Psychology. 2010; 11(1):21-38.

[14] Hankin BL, Abramson LY. Development of gender differences in depression: An elaborated cognitive vulnerability-transactional stress theory. Psychological Bulletin. 2001; 127(6):773-96. doi: 10.1037/0033-2909.127.6.773
[15] Beck A. T, Steer R.A, Brown G. K. Beck Depression Inventory $-2^{\text {nd }}$ edition manual. San Antonio: The Psychological Corporation; 1996

[16] Kapci EG, Uslu R, Turkcapar H, Karaoglan A. Beck Depression Inventory II: Evaluation of the psychometric properties and cut-off points in a Turkish adult population. Depression \& Anxiety. 2008; 25(10):104-110. doi: 10.1002/ da. 20371

[17] Ghassemzadeh H, Mojtaba'i R, Karamghadiri N, Ebrahimkhani N. Psychometric properties of a Persian-language version of the Beck Depression Inventory-Second edition: BDI-II-PERSIAN. Depression \& Anxiety. 2005; 21(4):185-92 doi: 10.1002/da.20070

[18] Carmody DP. Psychometric characteristics of the Beck Depression Inventory-II with college students of diverse ethnicity. International Journal of Psychiatry in Clinical Practice. 2005; 9(1):22-8. doi: 10.1080/13651500510014800

[19] Rajabi GhR, Karjoo Kasmaei S. [Psychometric propertie Beck Depression Inventory-Second edition (BDI-II-Persian) (Persian)]. Educational Measurement. 2012; 10(3):139-157.

[20] Beck AT, Brown G, Steer RA, Weissman AN. Factor analysis of the Dysfunctional Attitude Scale in a clinical population. Psychological Assessment. 1991; 3(3):478-83. doi: 10.1037/1040-3590.3.3.478

[21] Nolen-Hoeksema S, Morrow J. A prospective study of depression and posttraumatic stress symptoms after a natural disaster: The 1989 Loma Prieta earthquake. Journal of Personality \& Social Psychology. 1991; 61(1):115-21. doi 10.1037/0022-3514.61.1.115

[22] Treynor W, Gonzalez R, Nolen-Hoeksema S. Ruminative reconsidered: A psychometric analysis. Cognitive Therapy \& Research. 2003; 27(3):247-259. doi: 10.1023/a:1023910315561

[23] Luminet $O$. Measurement of depressive rumination and associated constructs. In Papageorgiou C, Wells A, editors. Depressive Rumination: Nature, Theory and Treatment New York: Wiley \& Sons. 2004.

[24] Abela JRZ, Hankin BL. Cognitive vulnerability to depression in children and adolescents: A developmental psychopathology perspective. In Abella JRZ, Hankin BG, editors. Handbook of Depression in Children and Adolescents. New York: Guilford Publications, Inc.; 2008

[25] Abela JRZ, Skitch SA. Dysfunctional attitudes, selfesteem, and hassles: Cognitive vulnerability to depression in children of affectively ill parents. Behaviour Research \& Therapy. 2007; 45(6):1127-40. doi: 10.1016/j.brat.2006.09.011

[26] D'Alessandro DU, Burton KD. Development and validation of the dysfunctional attitudes scale for children: Tests of Beck's Cognitive Diathesis-Stress Theory of Depression, of its causal mediation component, and of developmental effects. Cognitive Therapy \& Research. 2006; 30(3):335-53. doi: 10.1007/s10608-006-9046-5

[27] Alloy LB, Abramson LY, Gibb BE, Crossfield AG, Pieracc AM, Spasojevic J, et al. Developmental antecedents of cognitive vulnerability to depression: Review of findings from the cognitive vulnerability to depression project. Current findings and future directions. In Alloy LB, Rishkind JH, editors. Cognitive Vulnerability to Emotional Disorders. New Jersey: Paulist Press; 2006 
[28] Joormann J. Differential effects of rumination and dysphoria on the inhibition of irrelevant emotional material: Evidence from a negative priming task. Cognitive Therapy \& Research. 2006; 30(2):149-60. doi: 10.1007/s10608-006-9035-8

[29] Moulds ML, Kandris E, Starr S, Wong ACM. The relationship between rumination, avoidance and depression in a non-clinical sample. Behaviour Research \& Therapy. 2007; 45(2):251-61. doi: 10.1016/j.brat.2006.03.003

[30] Dobson KS, Dozois DJA. Risk factors in depression. New York: Elsevier; 2008. 